\title{
Studies of Atmospheric Parameters during SW Monsoon Period Associated with Severe Cyclone Aila and Lightning Occurrence over Ranchi Region
}

\author{
Abhay Srivastava, ${ }^{1,2,3}$ Manoj Kumar, ${ }^{1}$ and Arun K. Dwivedi ${ }^{1,2}$ \\ ${ }^{1}$ Centre of Excellence and Climatology, Birla Institute of Technology, Mesra, Ranchi 835215, India \\ ${ }^{2}$ Electrical and Electronics Engineering Department, Birla Institute of Technology, Mesra, Ranchi 835215, India \\ ${ }^{3}$ Electronics and Communication Engineering Department, Birla Institute of Technology, Mesra, Ranchi 835215, India
}

Correspondence should be addressed to Abhay Srivastava, abhaysrivastava2313@gmail.com

Received 19 April 2012; Accepted 25 June 2012

Academic Editors: T. Georgiadis and Z. Xie

Copyright ( $) 2012$ Abhay Srivastava et al. This is an open access article distributed under the Creative Commons Attribution License, which permits unrestricted use, distribution, and reproduction in any medium, provided the original work is properly cited.

\begin{abstract}
A number of events are happening every time in the atmosphere in which much of them are randomly generated. Parameters are varying daily like temperature, humidity, electric field, and wind speed. Variation on surface layer parameters, events thunderstorms, earthquake, volcanoes, cyclone, tsunami, and so forth are occurring. Study and correlation between surface layer parameter and occurrence are greatly required in current research scenario. A comparative study about atmospheric parameters has been done just after the Aila; in the day when lightning occurred and correlation coefficients between these parameters are observed.
\end{abstract}

\section{Introduction}

A common feature of the weather during the premonsoon season (March-May) over the Indo-Gangetic Plain and Northeast India is the outburst of severe local convective storms, commonly known as "Norwesters" or "Kalbaishakhi." It continued to move in a northerly direction across West Bengal. Norwesters are mesoscale convective systems which can develop under the large-scale envelope of the seasonal, low-level trough over the West Bengal-BiharJharkhand belt, with a possible embedded low-pressure area. These severe thunderstorms associated with thunder, squall lines, lightning, torrential rain, and hail cause extensive loss in agriculture, damage to property, and also loss of life. The casualties reported due to lightning associated with thunderstorms in this region are among the highest in the world. In India, $72 \%$ of tornadoes are associated with Nor'westers. These severe thunderstorms have significant socioeconomic impact in the eastern and northeastern parts. The formation, intensification, and propagation of thunderstorms are mostly governed by the synoptic situation and localized thermodynamic conditions of the atmosphere
[1]. The microphysical and electrical characteristics are known to significantly affect the formation and the intensity of precipitation. Severe cyclone Aila started in the month of May 2009 from the Bay of Bengal. A severe cyclonic storm (SCS) Aila crossed West Bengal coast near Sagar Island between 1330 and 1430 hrs IST of May 25th, 2009. These cyclones are formed by clouds and charge separation in the clouds. As known, physics of lightning is a variation in electric field, that is, dependable on charge separation generated in clouds [2]. This charge separation is due to dust storm, high wind velocity, cyclone, and ever Aila. After cyclone was over, rain occurred over the region followed by strong lightning activity during the first week of June. In this work, the authors analyzed the atmospheric parameters in the day of lightning and found the correlation coefficient between these parameters.

\section{Data Source and Method of Analysis}

Ranchi (Mesra) lies entirely in humid subtropical monsoon area of India (Lat. $23^{\circ} 24^{\prime} 44.22^{\prime \prime} \mathrm{N}$, long. $85^{\circ} 26^{\prime} 25.82^{\prime \prime}$, 
Elev. 609 MASL, and Time zone UTC/GMT +5:30). For the collection of atmospheric electric field (AEF) data, an Electric Field Meter (EFM) has installed which measures the electric field every second and every minute [3]. For the collection of other atmospheric parameters like Mean Wind Speed (WS), Relative Humidity (RH), and Air Temperature (AT), a 32-meter micrometeorological tower has installed. According to our necessity of parameters measurement, this micrometeorological tower has been designed. Instruments were installed at different logarithmic heights such as $1,2,4$, 8,16 , and 32 meters.

As known in the literature, Aila was a tropical cyclone. The term "tropical" refers to both the geographic origin of these systems, which form almost exclusively in tropical regions of the globe, and their formation in maritime tropical air masses. The term "cyclone" refers to such storms' cyclonic nature, with counterclockwise rotation in the Northern Hemisphere and clockwise rotation in the Southern Hemisphere. Depending on its location and strength, a tropical cyclone is referred to by names. Any cyclones develop when the atmospheric conditions around a weak disturbance in the atmosphere are favorable. Atmospheric conditions are drastically changed, whenever there is a possibility of any disaster. In normal days weather parameter is analyzed by Pandey et al. (2008) and they evaluated interrelationship in the meteorological data [4]. So it is necessary to analyze all the atmospheric parameters. In the Ranchi region, these cyclones are responsible of lightning occurrence [5].

As mentioned previously, authors are analyzing different atmospheric parameters, diurnal variation in the day when lightning occurred after the Aila, statistics of these parameters, and the correlation coefficient between these parameters. Correlation coefficient $\rho$ observed using Karl Pearson developed formula to measure the degree of linear relationship between two parameters

$$
\rho_{x y}=\frac{C_{x y}}{\sigma_{x} \sigma_{y}},
$$

where $C_{x y}$ is the covariance, $\sigma_{x}$ and $\sigma_{y}$ are the standard deviation of the variable.

\section{Results and Discussion}

In the results, authors firstly show statistics of atmospheric parameters AEF, RH, WS, and AT as in Table 1.

Changes in atmospheric parameters after severe cyclone Aila have been shown when the lightning occurred in the observational region. In all figures time is taken in minutes and starts from midnight local time. The following results come out from the analysis.

(1) Wind speed gets its maximum value just before lightning stroke as in Figure 1(a). The wind speed is shown on different height, and on the maximum height it was recorded maximum just before the lightning occurrence.
TABLE 1: Statistics of observed atmospheric parameter.

\begin{tabular}{lcccc}
\hline \multirow{2}{*}{ Statistical parameters } & \multicolumn{4}{c}{ Atmospheric variables } \\
& RH $(\%)$ & AT $\left({ }^{\circ} \mathrm{C}\right)$ & WS $(\mathrm{km} / \mathrm{h})$ & AEF $(\mathrm{v} / \mathrm{m})$ \\
\hline Sample size & 1440 & 1440 & 1440 & 1440 \\
Range & 47.70 & 10.36 & 18.26 & 9760 \\
Mean & 64.4105 & 27.6475 & 2.1771 & -3.3598 \\
Variance & 215.834 & 7.1360 & 2.7579 & 152070 \\
Standard deviation & 14.6913 & 2.6713 & 1.6607 & 389.9589 \\
Skewness & -0.4018 & 0.0971 & 4.1949 & 7.7090 \\
Kurtosis & 1.6934 & 2.0376 & 29.4358 & 108.2816 \\
\hline
\end{tabular}

TABLE 2: Correlation coefficient matrix of atmospheric parameter.

\begin{tabular}{lcccc}
\hline Correlation & AT & RH & WS & AEF \\
\hline AT & 1 & -0.8796 & 0.1234 & -0.1369 \\
RH & -0.8796 & 1 & -0.2163 & 0.0959 \\
WS & 0.1234 & -0.2163 & 1 & 0.1642 \\
AEF & -0.1369 & 0.0959 & 0.1642 & 1 \\
\hline
\end{tabular}

(2) Temperature abruptly goes down just after the lightning stroke in day time, where in normal case temperature follows its regular curve as in Figure 1(b). Lower height temperature was more in comparison to upper height in normal time but in the case of lightning lower height temperature recorded less. In the region, behind this the heat reflection in the normal time at ground is high over the rainy and lightning occurrence time.

(3) Humidity abruptly goes high just after the lightning stroke in day time where in normal case temperature follows its regular curve as in Figure 1(c). The humidity at upper height was high in comparison to lower height but when the lightning occurred it was vice versa. The region behind this the heat reflection reduces the humidity.

(4) Electric field changes in normal days are approximately 120 volts/meter, but when lightning occurred AEF increased on maximum level that can be up to 40 kilovolts/meter. The variation of AEF is shown in Figure 1(d). Normally AEF was 120 volts/meter, but in the time of lightning it was suddenly increased up to 7000 volts/meter.

All the previously observed parameters are correlated to each other. The correlation coefficient in these parameters is shown in Table 2. It is observed that the correlation between $\mathrm{RH}$ and AT is very high, but with the WS it was low. At last, the correlation between AT, WS, and RH with the AEF is very low, it is nearly zero, yet this type of studies will be helpful for the lightning alarming system with consideration of the fairweather atmospheric parameters.

\section{Conclusion}

Surface atmosphere interactions daily affect atmospheric processes, yet the results from these observations indicate 


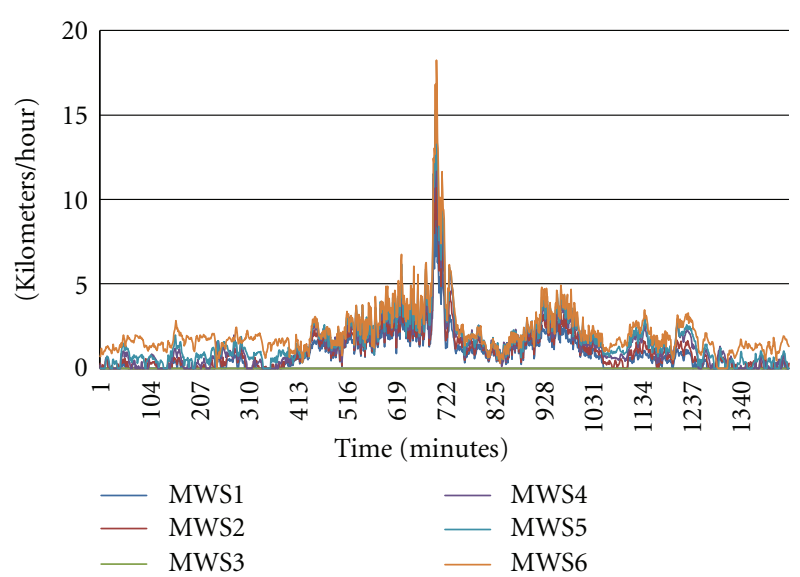

(a)

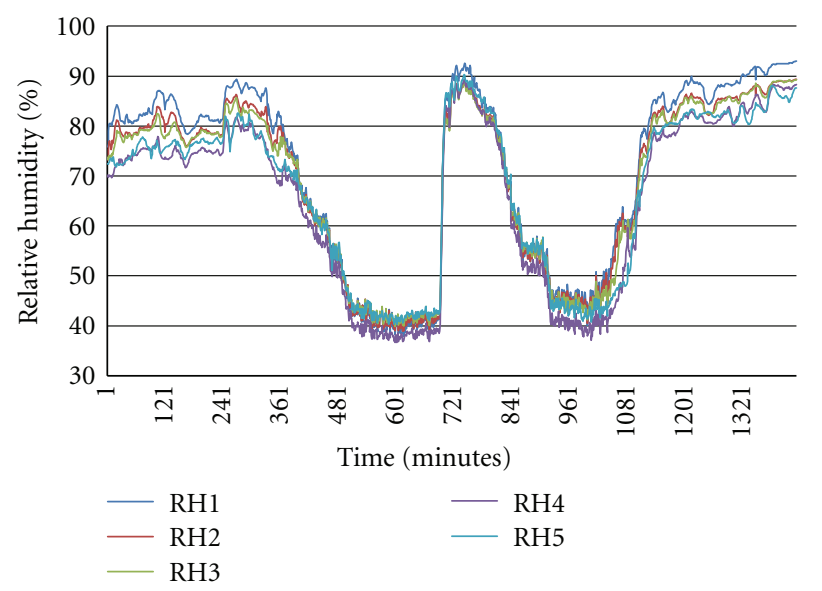

(c)

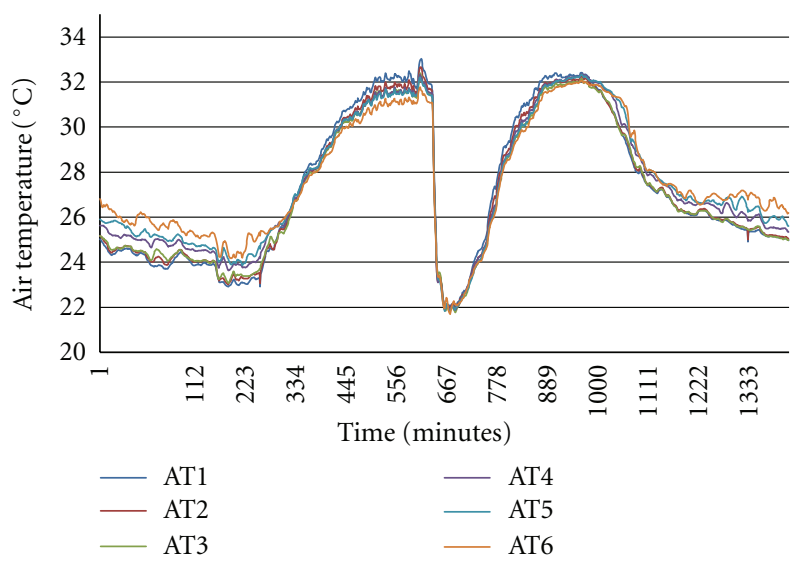

(b)

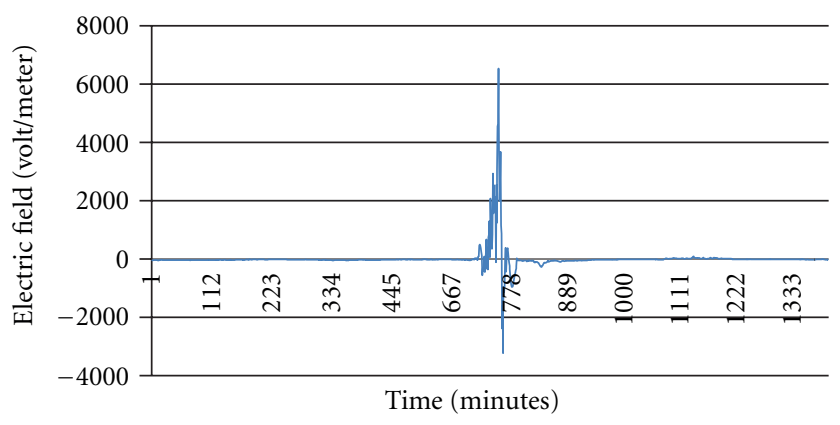

FIGURE 1: Atmospheric parameters diurnal variation on different height.

that after tropical cyclone Aila parameters will change on their regular process. The results are able to improve our understanding of the role of meteorological parameters. As mentioned previously, different atmospheric parameters are analyzed, and their variations are shown in the figures. All studied data do not follow their regular curve before lightning strike. On the basis of daily pattern, it will be easy in nowcasting purpose. The warning of lightning will be possible if all the data are correlated. It is clearly observed that lightning occurred in the cyclones or thunderstorm.

\section{Acknowledgments}

This research work is supported by Government of India, Ministry and Department of Science and Technology. The authors are thankful to them for their support and sponsorship. A. Srivastava is especially thankful to provide fellowship as INSPIRE fellow IF10631 for this work. They are also thankful to Department of Science and Technology, Government of Jharkhand, India for funding for the lightning research.

\section{References}

[1] C. D. Ahrens, Meteorology Today: An Introduction to Weather, Climate, and the Environment, West publishing, New York, NY, USA, 5th edition, 1994.

[2] V. A. Rakov and M. A. Uman, Lightning Physics and Effects, Cambridge University Press, 2005.

[3] S. Pulinets, G. Bisiacchi, J. Berlinski, M. Dunajecka, and A. Vega, "First results of the new type of measurements of atmospheric electric field in Mexico," Bol-e, no. 4, 2006.

[4] S. Pandey, M. Kumar, and N. C. Mahanti, "Evaluating interrelationship of meteorological parameters using regression model: a case study from Ranchi, Jharkhand, India," Indian Journal of Soil Conservation, vol. 36, no. 3, pp. 136-143, 2008.

[5] M. Fullekrug, "The contribution of intense lightning discharges to the global atmospheric electric circuit during April 1998," Journal of Atmospheric and Solar-Terrestrial Physics, vol. 66, no. 13-14, pp. 1115-1119, 2004. 

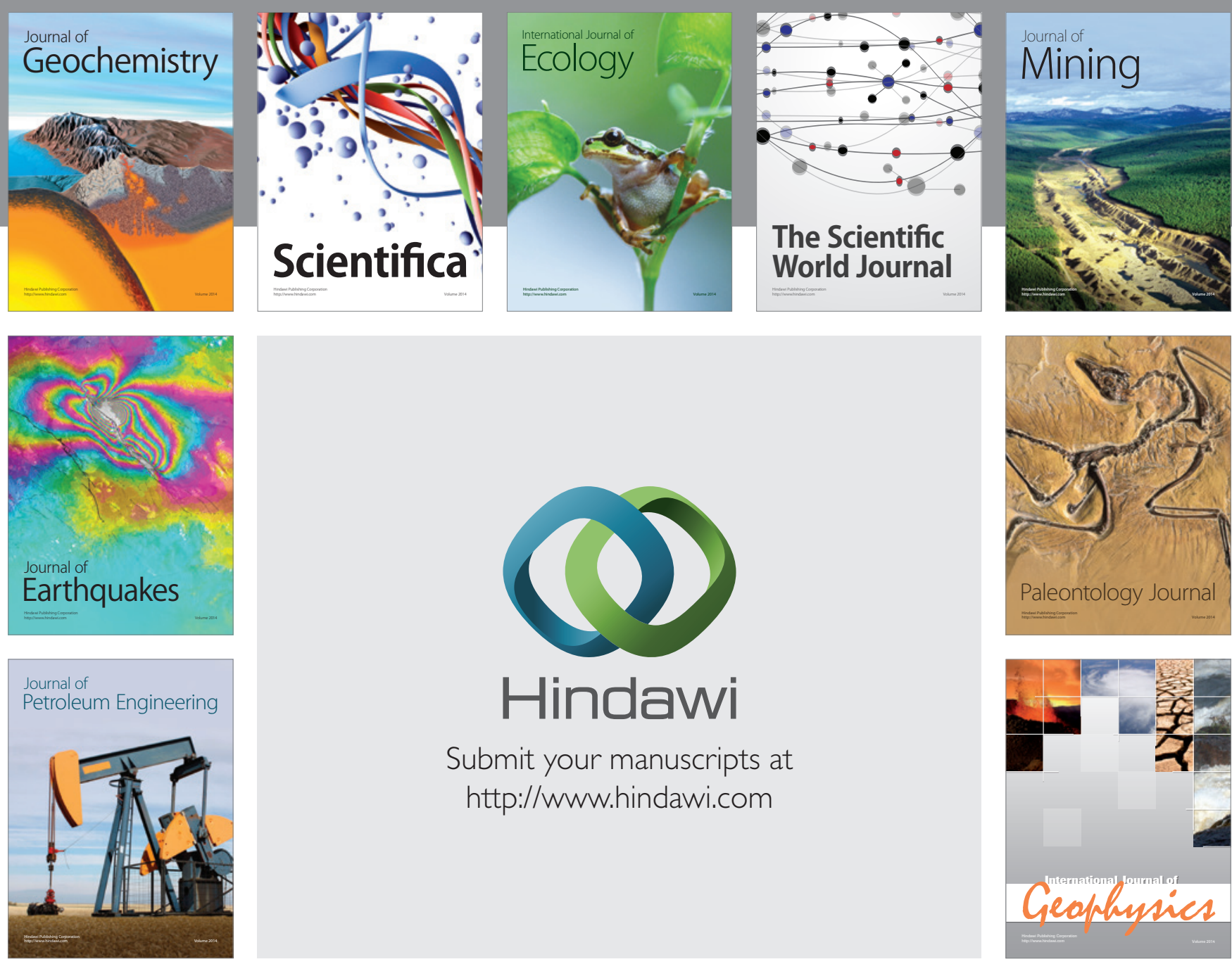

Submit your manuscripts at

http://www.hindawi.com
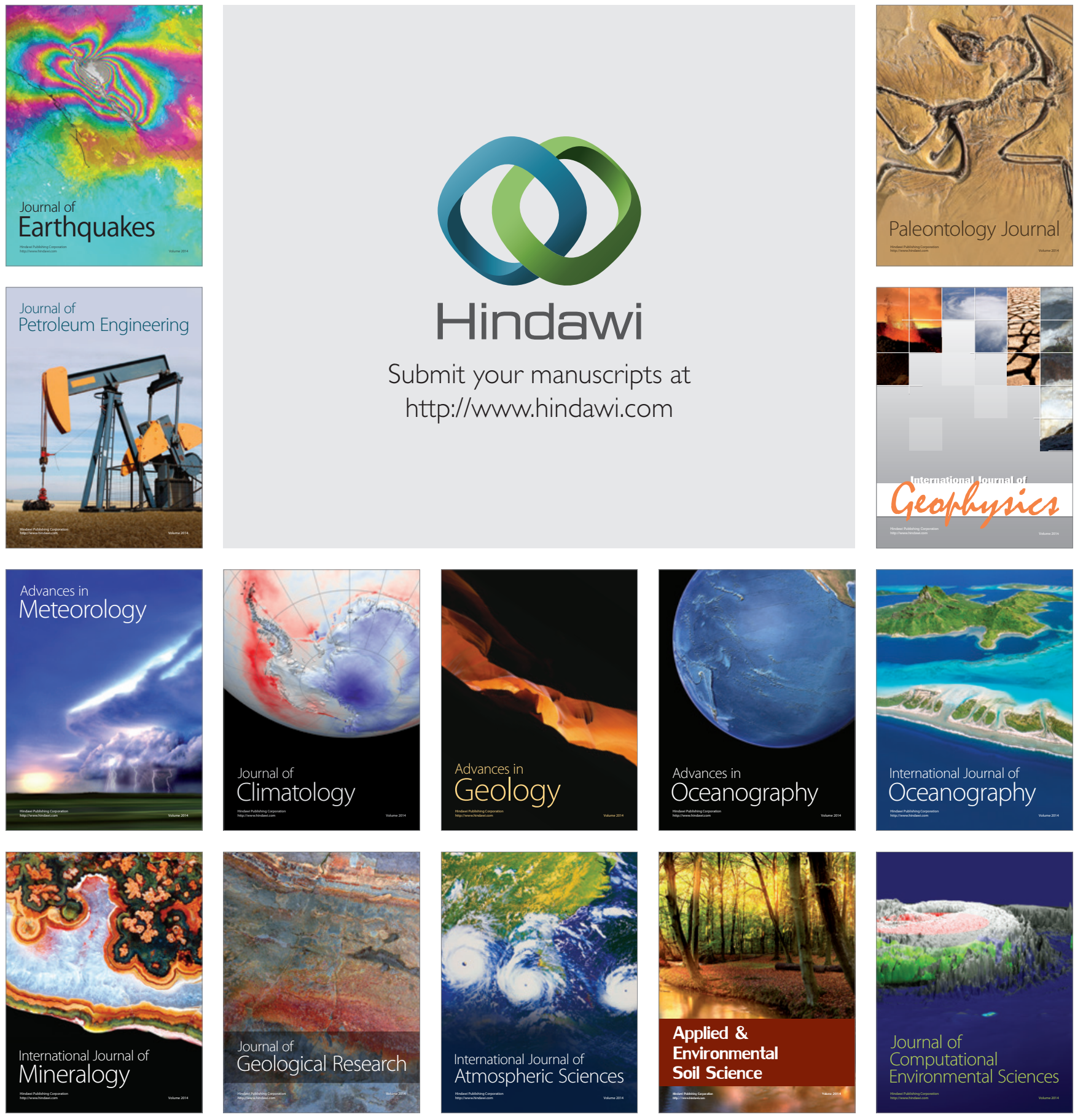